\title{
PRODUTIVIDADE E QUALIDADE DE TUBÉRCULOS DE BATATA EM FUNÇÃO DE DOSES E PARCELAMENTOS DE NITROGÊNIO E POTÁSSIO
}

\author{
Productivity of potato tubers in function of the doses and time of nitrogen and \\ potassium application
}

\author{
Adriana Dias Cardoso ${ }^{1}$, Marco Antônio Rezende Alvarenga², Thiago Lima Melo ${ }^{3}$, Anselmo Eloy Silveira Viana ${ }^{4}$
}

\begin{abstract}
RESUMO
Objetivou-se avaliar o efeito de doses e épocas de aplicação de adubo mineral sobre a produtividade e qualidade de batata na região centro sul da Bahia. Foram utilizadas 3 doses de N e K (75\% da dose recomendada; dose recomendada de acordo com a análise do solo e $125 \%$ da dose recomendada); e 5 épocas de aplicação (100\% no plantio; $1 / 3$ no plantio e $2 / 3$ na tuberização; $50 \%$ no plantio e $50 \%$ na tuberização; $1 / 3$ no plantio, 1/3 na tuberização e 1/3 25 dias após a tuberização; $1 / 4$ no plantio, 1/4 na tuberização, 1/4 25 dias após a tuberização e 1/4 50 dias após a tuberização). O delineamento experimental utilizado foi o de blocos ao acaso, em esquema fatorial 5 x 3, com quatro repetições. As características avaliadas foram: massa média dos tubérculos; produtividade de tubérculos; produtividade de tubérculos graúdos, massa seca, firmeza, sólidos solúveis, acidez total titulável e açúcares redutores. O parcelamento de $\mathrm{N}$ e $\mathrm{K}$ em duas aplicações (50\% no plantio e $50 \%$ na tuberização) favoreceu maior produtividade de tubérculos em relação à aplicação total do adubo. A época de aplicação e as doses de $\mathrm{N}$ e K não promoveram variações significativas no teor de massa seca, acidez total titulável, sólidos solúveis e teor de açúcares redutores dos tubérculos da cultivar Vivaldi.
\end{abstract}

Termos para indexação: Solanum tuberosum L., adubação, pós-colheita.

\begin{abstract}
With the purpose of assessing the effect of doses and application times of mineral fertilizers on the production and quality of tubercle potato, this experiment was carried out in the south center of Bahia and at the Universidade Estadual do Sudoeste da Bahia-UESB. Five application times were used (100\% upon planting; $1 / 3$ upon planting and 2/3 upon tuberization; $50 \%$ upon planting and 50\% upon tuberization; $1 / 3$ upon planting, $1 / 3$ upon tuberization and $1 / 325$ days after tuberization; $1 / 4$ upon planting, $1 / 4$ upon tuberization, $1 / 425$ days after tuberization and 1/4 50 days after tuberization) and 3 doses of $\mathrm{N}$ and $\mathrm{K}$ ( $75 \%$ of the recommended dose; recommended dose according to soil analysis; $125 \%$ of the recommended dose; recommended dose according to soil analysis). The experimental outline was the factorial one $(5 \times 3)$, with plots arranged in randomized blocks with four repetitions. Tubercle productivity was assessed, as well as tubercle average weight, great tubercles productivity, great tubercles average weight, firmness, soluble solids, total titulable acidity and reducing sugars. The split application of $\mathrm{N}$ and $\mathrm{K}$ fertilization (50\% upon planting and $50 \%$ upon tuberization) favored higher tubercles productivity in relation to the total fertilizer application. The application time and the doses of $\mathrm{N}$ and $\mathrm{K}$ did not promote significant responses in the dry mass, total titulable acidity, soluble solids and content of reducing sugars in the tubercles potato Vivaldi.
\end{abstract}

Index terms: Solanum tuberosum L., fertilization, postharvest.

(Recebido em 3 de maio de 2007 e aprovado em 16 de agosto de 2007)

\section{INTRODUÇÃo}

A cultura da batata é altamente responsiva às alterações ambientais, inclusive àquelas de origem edáfica, principalmente relativo à fertilidade (BREGAGNOLI et al., 2003). Embora essa hortaliça responda bem à adição de nutrientes no solo, deve-se estar atento para não fornecêlos em excesso, especialmente o nitrogênio e o potássio
(BARCELOS et al., 2007). Excesso de nitrogênio pode estimular maior produção de folhagem, reduzir a massa seca e o amido nos tubérculos, retardar a maturação e prolongar a duração do período vegetativo. $\mathrm{O}$ excesso de potássio pode reduzir a produção, diminuir a massa seca e o amido nos tubérculos (REIS JÚNIOR, 1995).

A batata (Solanum tuberosum L.) é a hortaliça mais plantada no Brasil, com grande expansão econômica em

\footnotetext{
'Engenheira Agrônoma, Doutora - Departamento de Fitotecnia e Zootecnia/DFZ - Universidade Estadual do Sudoeste da Bahia/UESB - Cx. P. 95 45083-900 - Vitória da Conquista, BA - adriadk@bol.com.br

Engenheiro Agrônomo, Doutor, Professor Titular - Departamento de Agricultura/DAG - Universidade Federal de Lavras/UFLA - Cx. P. 3037 - $37200-000$ Lavras, MG - alvarengamarco@terra.com.br

${ }^{3}$ Engenheiro Agrônomo, Mestre - Departamento de Fitotecnia e Zootecnia/DFZ - Universidade Estadual do Sudoeste da Bahia/UESB - Cx. P. 95 45083-900 - Vitória da Conquista, BA - thiagolimelo@bol.com.br

${ }^{4}$ Engenheiro Agrônomo, Doutor, Professor Titular - Departamento de Fitotecnia e Zootecnia/DFZ - Universidade Estadual do Sudoeste da Bahia/UESB Cx. P. 95 - 45083-900 - Vitória da Conquista, BA - aviana@uesb.br
} 
vários estados, como Bahia e Goiás. O crescente incremento na produção é uma resposta frente à alta demanda de batata para o consumo in natura e processada.

Até hoje, a utilização indiscriminada de fertilizantes está presente nas áreas de cultivos de batata e, em conseqüência desse uso excessivo, ocorre o aumento do custo de produção, além da redução da qualidade dos tubérculos. Em geral, produtores de batata fazem uma única adubação no plantio ou fazem uma adubação de cobertura com $\mathrm{N}$, junto com a operação de amontoa (20 a 30 dias após o plantio). Vieira et al. (2002) recomendam o uso do parcelamento da adubação nitrogenada e potássica na cultura da batata, pois ele proporciona algumas vantagens como: menor perda por lixiviação (K e N), menor perda por volatilização $(\mathrm{N})$ e redução do efeito salino. Entretanto, mais estudos sobre a nutrição mineral em batateira são necessários em relação à produtividade e qualidade dos tubérculos, principalmente nas regiões que apresentam microclimas favoráveis ao cultivo dessa hortaliça, a exemplo da Bahia e Goiás, onde ocorre um incremento da crescente produção agrícola.

Diante disso, objetivou-se no presente trabalho avaliar o efeito de doses e épocas de aplicação de $\mathrm{N}$ e K, sobre a produtividade e qualidade de batata.

\section{MATERIAL E MÉTODOS}

O experimento foi conduzido na Fazenda Progresso II, localizada no distrito de Cascavel, no município de Mucugê, região centro sul da Bahia, a 1300'19" Latitude Sul e $41^{\circ} 22^{\prime} 15^{\prime \prime}$ Longitude Oeste de Greenwich, com altitude média de $984 \mathrm{~m}$. O solo da área experimental foi classificado em Latossolo Amarelo, com topografia plana, o qual apresentou os seguintes resultados de análise química para a camada de $0-20 \mathrm{~cm}$ de profundidade (após a calagem): $\mathrm{pH}$ em $\mathrm{H}_{2} \mathrm{O}(1: 2,5)=5,2 ; \mathrm{P}\left(\mathrm{mg} / \mathrm{dm}^{3}\right)=48 ; \mathrm{K}^{+}$, $\mathrm{Al}^{3+}, \mathrm{Ca}^{2+}, \mathrm{Mg}^{2+}$ : $\mathrm{H}^{+}+\mathrm{Al}^{3+}$, S.B, CTC efetiva e CTC a pH $7,0\left(\mathrm{cmol}_{\mathrm{c}} / \mathrm{dm}^{3}\right)=0,18 ; 0,3 ; 1,0 ; 1,5 ; 1,7 ; 2,7 ; 3,0$ e 4,4, respectivamente; $\mathrm{m}(\%)=10 ; \mathrm{V}(\%)=61 \% ; \mathrm{M} . \mathrm{O}\left(\mathrm{g} / \mathrm{dm}^{3}\right)=0$; $\mathrm{Cu}^{++}, \mathrm{Mn}^{++}, \mathrm{Zn}^{++}$e $\mathrm{Fe}^{++}\left(\mathrm{mg} / \mathrm{dm}^{3}\right)=2,60 ; 1,40 ; 2,70$ e 24,00 , respectivamente.

O delineamento experimental utilizado foi o de blocos ao acaso, em esquema fatorial $5 \times 3$, totalizando 15 tratamentos, com 4 repetições. Os tratamentos foram constituídos por 5 épocas de aplicação de adubação de nitrogênio e potássio (1. $100 \%$ no plantio; $2.1 / 3$ no plantio e $2 / 3$ na tuberização (28 dias após o plantio); $3.50 \%$ no plantio e $50 \%$ na tuberização; 4 . $1 / 3$ no plantio, $1 / 3$ na tuberização e 1/3 25 dias após a tuberização; 5. 1/4 no plantio, 1/4 na tuberização, 1/4 25 dias após a tuberização e 1/4 50 dias após a tuberização e 3 doses de nitrogênio e potássio (1: $75 \%$ da dose recomendada (105 kg.ha ${ }^{-1}$ de N e $210 \mathrm{~kg}$.ha ${ }^{-1}$ de K), 2: dose recomendada de acordo com a análise do solo (140 kg de $\mathrm{N}$ e $280 \mathrm{~kg}$ de $\mathrm{K}$ ), 3: $125 \%$ da dose recomendada (175kg.ha-1 de N e 350 kg.ha-1 de K). A parcela experimental foi composta por 42 plantas, das quais apenas 6 foram úteis, em uma área útil de $1,44 \mathrm{~m}^{2}$. Utilizouse bordadura externa, margeando-se cada parcela do experimento.

O preparo do solo foi feito de acordo com o recomendado para a cultura da batata. A adubação foi feita manualmente no sulco de plantio, obedecendo-se aos tratamentos. Utilizou-se o adubo 4-14-8 e o superfosfato simples na primeira aplicação para todos os tratamentos. Nas aplicações dos parcelamentos 2, 3, 4 e 5, utilizou-se uréia e cloreto de potássio. O plantio dos tubérculossemente da cultivar Vivaldi foi efetuado manualmente, no dia 3 de maio de 2006, utilizando o espaçamento 0,3 m entre plantas e $0,8 \mathrm{~m}$ entre linhas de plantio, resultando em uma população de 41.667 plantas.ha ${ }^{-1}$.

O controle fitossanitário foi feito por meio de aplicações preventivas e de controle com defensivos químicos, sempre que necessário. A aplicação de agroquímicos seguiu as práticas usadas na região. E a irrigação foi realizada por meio de um sistema de irrigação por pivô central, visando atender às necessidades hídricas do sistema solo-planta.

Após a colheita, realizada por meio do arranquio manual, foram avaliadas as seguintes características: a) massa média dos tubérculos, determinada pela divisão da produção total dos tubérculos pelo número de tubérculos da parcela; b) produtividade de tubérculos, obtida pela coleta e pesagem de todas as plantas contidas nas linhas centrais da área útil de cada parcela; c) produtividade de tubérculos graúdos, obtida pela pesagem deles com diâmetro transversal igual ou superior que $45 \mathrm{~mm}$; d) massa seca, obtida pela fórmula: peso da massa seca/ peso da massa fresca x 100; e) firmeza $(\mathrm{N})$ : determinada com o auxílio texturômetro TR, modelo WA68, Italy. Foram feitas quatro medições por tubérculo, na região equatorial; g) sólidos solúveis (\%): determinada por meio de refratometria, em refratômetro ATTO Instruments, WYT-4, Hong Kong e expressos em \%, segundo a AOAC (1992); h) acidez total titulável (\% de ácido cítrico. $100 \mathrm{~g}^{-1}$ de polpa): determinada por meio de titulação com solução de $\mathrm{NaOH} 0,1 \mathrm{~N}$ e indicador fenolftaleína, de acordo com o Instituto Adolfo Lutz (1985); e i) açúcares redutores (\%): foram extraídos pelo método de Lane Enyon, citado na AOAC (1990) e identificados pelo método redutométrico de SomogyNelson (SOUTHGATE, 1991). 
A análise estatística foi realizada utilizando-se o programa Software SISVAR (FERREIRA, 2003), procedendo-se à análise de variância e, posteriormente, as médias dos tratamentos foram comparadas pelo teste de Tukey, a 5\% de probabilidade.

\section{RESULTADOS E DISCUSSÃO}

Houve interação significativa entre parcelamento e dose para a característica massa média de tubérculos. Para todas as doses utilizadas, não foi constatada diferença significativa entre os parcelamentos. Entretanto, para a aplicação total do adubo no plantio, a massa média de tubérculos foi superior com o uso da maior dose de $\mathrm{N}$ e $\mathrm{K}$ em relação à dose recomendada e a menor dose de $\mathrm{N}$ e $\mathrm{K}$. Para o parcelamento 2 (1/3 no plantio e 2/3 na tuberização), a massa média de tubérculos foi maior com a dosagem recomendada e com a maior dose de $\mathrm{N}$ e K. E, para os demais parcelamentos, as diferentes dosagens não influenciaram no peso médio de tubérculos (Tabela 1). Segundo o Centro de Pesquisas Agrárias da Fundação Ruralcaja (2007), a massa média de tubérculos da cultivar Vivaldi, encontrado nas condições da Espanha é de, aproximadamente $170 \mathrm{~g}$. O valor é distinto dos obtidos neste trabalho, confirmando, assim, que fatores climáticos (Mucugê: temperatura média anual $23^{\circ} \mathrm{C}$ e precipitação média anual $681,7 \mathrm{~mm}$ ) e manejo da adubação podem influenciar na massa de tubérculos de batata.

O parcelamento do nitrogênio e de potássio exerceu influência na produtividade de tubérculos. A melhor resposta foi obtida com o uso do parcelamento 3 (50\% no plantio e $50 \%$ na tuberização) em relação ao não parcelamento e ao parcelamento 5 (1/4 no plantio, $1 / 4$ na tuberização, 1/4 25 dias após a tuberização e 1/4 50 dias após a tuberização (Tabela 1). Isso mostra que as diferentes formas de parcelamento da adubação nitrogenada e potássica, sob solo Franco Arenoso (com pequena capacidade de reter nutrientes), podem influenciar diferentemente o desempenho da batateira.

A produtividade média de tubérculos dos tratamentos estudados nos diferentes parcelamentos foi superior à produtividade média encontrada por Feltran (2002), nas cultivares Ágata (28.600 kg.ha $\left.{ }^{-1}\right)$, Liseta (37.200 kg.ha $\left.{ }^{-1}\right)$, Santana (27.600 kg.ha-1) e inferior na cultivar Mondial (50.100 kg.ha-1), em que foi feita uma aplicação no plantio com 4-14-8 e adubação de cobertura com 20-00-20. A produtividade média obtida em Mucugê/Ibicoara, maior produtor de batata do Nordeste, é de $35.000 \mathrm{~kg} \cdot \mathrm{ha}^{-1}$. Barcelos (2004) avaliou o efeito do parcelamento da adubação nitrogenada em cobertura na cultura da batata $\mathrm{e}$ constatou que o parcelamento das doses de $\mathrm{N}$ não influenciou a produtividade dos tubérculos da cultivar Monalisa. As produções médias encontradas por esse autor foram de $35.100 \mathrm{~kg} \cdot \mathrm{ha}^{-1}$ (100\% da aplicação de $\mathrm{N}$ na amontoa), $35.200 \mathrm{~kg} \cdot \mathrm{ha}^{-1}$ (50\% da aplicação de $\mathrm{N}$ na emergência e $50 \%$ na amontoa) e $38.000 \mathrm{~kg}^{-h^{-1}}$ (50\% da aplicação de $\mathrm{N}$ na amontoa e 50\% 15 dias após a amontoa).

Pelos dados da Tabela 1, verifica-se que os diferentes parcelamentos e doses de $\mathrm{N}$ e $\mathrm{K}$ influenciaram significativamente na produtividade de tubérculos graúdos. A maior dose de $\mathrm{N}$ e $\mathrm{K}$ proporcionou um incremento na produtividade de tubérculos graúdos em relação às demais doses e a utilização do parcelamento 3 (50\% no plantio e $50 \%$ na tuberização) apresentou melhor resposta em produtividade de tubérculos graúdos quando comparado somente com a aplicação total desses elementos no plantio. Os resultados apresentados mostram que há uma resposta da produtividade de tubérculos graúdos ao parcelamento e às doses de N e K. Segundo Andreatta (2003), a produtividade média comercial da cultivar Vivaldi é de, aproximadamente, $40.000 \mathrm{~kg} \cdot \mathrm{ha}^{-1}$, valor próximo ao obtido neste experimento. Carvalho et al. (2003) verificaram produtividade comercial de 35.980, 32.120, 29.380, 28.230 e 22.490 kg.ha ${ }^{-1}$, nas cultivares Bintje, Canoinhas, Liza, Monalisa e Achat, respectivamente. Feltran (2002) observou menores produtividades comerciais nas cultivares Ágata $\left(23.400 \mathrm{~kg} \cdot \mathrm{ha}^{-1}\right)$, Liseta (28.200 kg.ha ${ }^{-1}$ e Santana (19.700 kg.ha ${ }^{-1}$ ), que receberam aplicação no plantio com 4-14-8 e adubação de cobertura com 20-00-20. Nunes (2002) encontrou valores de produtividade comercial de 22.470, 20.540, 15.520, 14.520, 12.480, 9.060, 3.350 kg.ha-1 ${ }^{-1}$ nas cultivares Elvira, Monalisa, Santo Amor, Baronesa, Monte Bonito, Trapeira e Baraka, respectivamente.

A dose e o parcelamento da adubação nitrogenada e potássica não afetaram significativamente o teor de massa seca dos tubérculos de batata (Tabela 1). Os valores de massa seca, para a cultivar Vivaldi, estão abaixo dos intervalos mínimos requeridos para a obtenção de produtos fritos com ótimas características. Segundo Cacace et al. (1994), os teores de massa seca podem ser agrupados em: alto teor de massa seca (teores $>20,0 \%$ ), teor intermediário de massa seca (teores entre $18,0 \%$ a $19,9 \%$ ) e baixo teor de massa seca (teores $<17,9 \%$ ). A cultivar Vivaldi pertence ao grupo de baixo teor de massa seca, sendo recomendada para uso em saladas, purês, massas (FAEP, 2006). Feltran et al. (2004) encontraram valor médio de $16,4 \%$ de massa seca, nos tubérculos da cultivar Ágata, adubados com 414-8 (aplicação no plantio) e 20-00-20 (adubação de cobertura). Mallmann (2001), estudando o efeito da adubação na qualidade de batata, constatou que altas doses 
de nitrogênio favorecem a redução do teor de massa seca dos tubérculos. Pauletti \& Menarim (2004), estudando efeito de fontes ( $\mathrm{KCl}$ e $\mathrm{K}_{2} \mathrm{SO}_{4}$ ), épocas ( $50 \%$ da aplicação em pré-plantio mais $50 \%$ no sulco, e $50 \%$ no sulco mais $50 \%$ na amontoa) e doses $\left(0,200,400\right.$ e $\left.600 \mathrm{~kg}^{-h^{-1}} \mathrm{de}_{2} \mathrm{O}\right)$ de adubação potássica em batata da cultivar Binjte, verificaram que o aumento dos teores foliares de potássio diminuíram a massa seca dos tubérculos, afetando sua qualidade.

Pelos dados da Tabela 2, verifica-se que a utilização do parcelamento e da dose da adubação nitrogenada e potássica não alterou a firmeza dos tubérculos "in natura", sólidos solúveis, acidez total titulável e açúcares redutores.
A firmeza é uma das principais características para o consumidor que adquire o produto "in natura", embora seja de menor importância para a indústria (ANDREU, 2005). Coelho (1998), avaliando a qualidade de fritura de duas cultivares de batata armazenadas em atmosfera modificada em temperatura ambiente e sob refrigeração, encontrou valores superiores de firmeza ( $100 \mathrm{~N}$ e $110 \mathrm{~N}$, em Baraka e Achat, respectivamente). Além disso, foi observado também que apenas a cultivar Baraka não exibiu perda de firmeza durante o armazenamento, com relação ao valor inicial (tubérculos analisados logo após a colheita). Entretanto, Feltran (2002) avaliando dezoito cultivares de batata, adubadas com 4-14-8, no sulco de plantio,

Tabela 1 - Massa média dos tubérculos, produtividade de tubérculos, produtividade de tubérculos graúdos e massa seca, em função do parcelamento e doses de nitrogênio e potássio em batata cv. Vivaldi. UFLA, Lavras, MG, 2007.

\begin{tabular}{|c|c|c|c|c|c|c|}
\hline \multirow{3}{*}{ Dose } & \multicolumn{5}{|c|}{ Massa média de tubérculos $(\mathrm{g})$} & \multirow{3}{*}{ Média } \\
\hline & \multicolumn{5}{|c|}{ Parcelamento } & \\
\hline & 1 & 2 & 3 & 4 & 5 & \\
\hline $75 \%$ da dose recom. & $86,67 \mathrm{aB}$ & $91,79 \mathrm{aB}$ & $100,50 \mathrm{aA}$ & $89,84 \mathrm{aA}$ & $103,87 \mathrm{aA}$ & 94,53 \\
\hline Recomendada & $92,97 \mathrm{aB}$ & $107,85 \mathrm{aA}$ & $101,66 \mathrm{aA}$ & $101,76 \mathrm{aA}$ & $101,49 \mathrm{aA}$ & 101,15 \\
\hline $125 \%$ da dose recom & $116,71 \mathrm{aA}$ & $111,91 \mathrm{aA}$ & $111,74 \mathrm{aA}$ & $104,12 \mathrm{aA}$ & $100,14 \mathrm{aA}$ & 108,92 \\
\hline Média & 98,78 & 103,85 & 104,63 & 98,57 & 101,83 & \\
\hline \multirow[t]{2}{*}{ C.V.(\%) } & 9,04 & & & & & \\
\hline & \multicolumn{5}{|c|}{ Produtividade de tubérculos $\left(\mathrm{kg} \cdot \mathrm{ha}^{-1}\right)$} & \\
\hline \multirow[t]{2}{*}{ Dose } & \multicolumn{5}{|c|}{ Parcelamento } & Média \\
\hline & 1 & 2 & 3 & 4 & 5 & \\
\hline $75 \%$ da dose recom. & 38949,65 & 43750,00 & 46449,65 & 43168,41 & 45399,31 & $43543,40 \mathrm{~A}$ \\
\hline Recomendada & 45668,40 & 46649,31 & 51649,31 & 51848,96 & 42994,79 & $47762,15 \mathrm{~A}$ \\
\hline $125 \%$ da dose recom & 47578,13 & 52725,70 & 55581,60 & 48732,64 & 49157,99 & $50755,21 \mathrm{~A}$ \\
\hline Média & $44065,39 b$ & $47708,34 \mathrm{ab}$ & $51226,85 a$ & $47916,67 \mathrm{ab}$ & $45850,70 b$ & \\
\hline \multirow[t]{2}{*}{ C.V.(\%) } & 9,03 & & & & & \\
\hline & \multicolumn{5}{|c|}{ Produtividade de tubérculos graúdos $\left(\mathrm{kg} \cdot \mathrm{ha}^{-1}\right)$} & \\
\hline \multirow[t]{2}{*}{ Dose } & \multicolumn{5}{|c|}{ Parcelamento } & Média \\
\hline & 1 & 2 & 3 & 4 & 5 & \\
\hline $75 \%$ da dose recom. & 27925,34 & 34835,07 & 39626,73 & 35164,93 & 39166,67 & $35343,75 \mathrm{C}$ \\
\hline Recomendada & 37118,06 & 40260,42 & 44244,79 & 42065,97 & 37473,96 & $40232,64 \mathrm{~B}$ \\
\hline $125 \%$ da dose recom & 42760,42 & 45303,82 & 49097,22 & 41770,83 & 41996,53 & $44185,76 \mathrm{~A}$ \\
\hline Média & $35934,61 b$ & $40133,10 \mathrm{ab}$ & $44322,91 \mathrm{a}$ & $39667,24 a b$ & $39545,72 \mathrm{ab}$ & \\
\hline \multirow[t]{4}{*}{ C.V.(\%) } & 11,44 & & & & & \\
\hline & \multicolumn{5}{|c|}{ Massa seca (\%) } & \\
\hline & \multicolumn{5}{|c|}{ Parcelamento } & Média \\
\hline & 1 & 2 & 3 & 4 & 5 & \\
\hline $75 \%$ da dose recom. & 15,44 & 15,03 & 15,75 & 14,41 & 16,04 & $15,33 \mathrm{~A}$ \\
\hline Recomendada & 15,56 & 15,21 & 15,36 & 14,24 & 15,46 & $15,17 \mathrm{~A}$ \\
\hline $125 \%$ da dose recom & 15,45 & 15,48 & 14,49 & 15,71 & 14,89 & $15,20 \mathrm{~A}$ \\
\hline Média & $15,48 \mathrm{a}$ & $15,24 a$ & $15,20 \mathrm{a}$ & $14,79 \mathrm{a}$ & $15,46 \mathrm{a}$ & \\
\hline C.V.(\%) & 5,60 & & & & & \\
\hline
\end{tabular}

*Médias seguidas de mesma letra minúscula nas linhas e maiúsculas nas colunas, não diferem entre si, a 5\% de probabilidade, pelo teste de Tukey. 
encontrou um variação de firmeza entre 5,97 a 8,9 N, valores esses abaixo do encontrado nesse trabalho.

Os teores de sólidos solúveis nos tubérculos de batata estão apresentados na Tabela 2, na qual se pode observar pequena variação nos valores de SS entre os tratamentos. Para Chitarra \& Chitarra (2005), o teor de sólidos solúveis totais é utilizado como uma medida indireta do teor de açúcares, podendo variar de $2 \%$ a $25 \%$ a depender da espécie, dos estádios de maturação e do clima. Pinelli et al. (2005) obtiveram valores próximos de sólidos solúveis para a cultivar Ágata (3,9\% a 4,7\%), logo após o processamento mínimo das batatas. Paschoalino et al. (1993), avaliando características de qualidade de seis cultivares de batata, observaram oscilação nos valores de sólidos solúveis de $5,1 \%$ a $6,8 \%$. Feltran et al. (2004) avaliaram a qualidade tecnológica e a utilização de tubérculos de batata, visando identificar a melhor forma de utilização e consumo. Esses autores encontraram valores de SS de 5,46\%, 5,32\%, 4,88\% e 3,91\% para Ágata, Picasso, Mondial e Solide, respectivamente e concluíram que os SS são influenciados pelo material genético.

O uso do parcelamento e da dose da adubação nitrogenada e potássica não contribuíram para o aumento da característica acidez total titulável nos tubérculos de batata da cultivar Vivaldi (Tabela 2). Bregagnoli (2006) obteve valores superiores ao encontrado neste trabalho,

Tabela 2 - Firmeza, sólidos solúveis, acidez total titulável e açúcares redutores, em função do parcelamento e doses de nitrogênio e potássio em batata cv. Vivaldi, Lavras, MG, 2007.

\begin{tabular}{|c|c|c|c|c|c|c|}
\hline \multicolumn{7}{|c|}{ Firmeza (N) } \\
\hline \multirow[t]{2}{*}{ Dose } & \multicolumn{5}{|c|}{ Parcelamento } & \multirow[t]{2}{*}{ Média } \\
\hline & 1 & 2 & 3 & 4 & 5 & \\
\hline $75 \%$ da dose recom. & 53,90 & 52,48 & 53,47 & 51,46 & 54,76 & $52,21 \mathrm{~A}$ \\
\hline Recomendada & 47,25 & 54,05 & 56,23 & 54,23 & 50,38 & $52,43 \mathrm{~A}$ \\
\hline $125 \%$ da dose recom & 52,02 & 52,16 & 53,41 & 50,91 & 53,53 & $52,41 \mathrm{~A}$ \\
\hline Média & $51,06 a$ & $52,90 \mathrm{a}$ & $54,37 \mathrm{a}$ & $52,20 \mathrm{a}$ & $52,89 a$ & \\
\hline \multirow[t]{2}{*}{ C.V.(\%) } & 11,47 & & & & & \\
\hline & \multicolumn{5}{|c|}{ Sólidos solúveis (\%) } & \\
\hline \multirow[t]{2}{*}{ Dose } & \multicolumn{5}{|c|}{ Parcelamento } & Média \\
\hline & 1 & 2 & 3 & 4 & 5 & \\
\hline $75 \%$ da dose recom. & 3,25 & 3,75 & 3,50 & 3,50 & 3,25 & $3,45 \mathrm{~A}$ \\
\hline Recomendada & 3,50 & 3,50 & 3,75 & 3,25 & 3,50 & $3,50 \mathrm{~A}$ \\
\hline $125 \%$ da dose recom & 3,25 & 3,50 & 3,50 & 3,50 & 3,25 & $3,40 \mathrm{~A}$ \\
\hline Média & $3,33 a$ & $3,58 \mathrm{a}$ & $3,58 \mathrm{a}$ & $3,42 \mathrm{a}$ & $3,33 a$ & \\
\hline \multirow[t]{2}{*}{ C.V.(\%) } & 16,00 & & & & & \\
\hline & \multicolumn{5}{|c|}{ Acidez total titulável (\%) } & \\
\hline \multirow[t]{2}{*}{ Dose } & \multicolumn{5}{|c|}{ Parcelamento } & Média \\
\hline & 1 & 2 & 3 & 4 & 5 & \\
\hline $75 \%$ da dose recom. & 0,153 & 0,160 & 0,145 & 0,138 & 0,160 & $0,151 \mathrm{~A}$ \\
\hline Recomendada & 0,160 & 0,175 & 0,160 & 0,160 & 0,175 & $0,166 \mathrm{~A}$ \\
\hline $125 \%$ da dose recom & 0,160 & 0,160 & 0,153 & 0,170 & 0,168 & $0,162 \mathrm{~A}$ \\
\hline Média & $0,158 \mathrm{a}$ & $0,165 a$ & $0,153 \mathrm{a}$ & $0,156 \mathrm{a}$ & $0,168 \mathrm{a}$ & \\
\hline \multirow[t]{2}{*}{ C.V.(\%) } & 12,09 & & & & & \\
\hline & \multicolumn{5}{|c|}{ Açúcares redutores (\%) } & \\
\hline \multirow[t]{2}{*}{ Dose } & \multicolumn{5}{|c|}{ Parcelamento } & Média \\
\hline & 1 & 2 & 3 & 4 & 5 & \\
\hline $75 \%$ da dose recom. & 0,065 & 0,038 & 0,055 & 0,083 & 0,065 & $0,061 \mathrm{~A}$ \\
\hline Recomendada & 0,065 & 0,078 & 0,048 & 0,070 & 0,063 & $0,065 \mathrm{~A}$ \\
\hline $125 \%$ da dose recom & 0,063 & 0,058 & 0,063 & 0,075 & 0,053 & $0,062 \mathrm{~A}$ \\
\hline Média & $0,064 a$ & $0,058 \mathrm{a}$ & $0,055 \mathrm{a}$ & $0,076 a$ & $0,060 \mathrm{a}$ & \\
\hline
\end{tabular}

*Médias seguidas de mesma letra minúscula nas linhas e maiúsculas nas colunas, não diferem entre si, a 5\% de probabilidade, pelo teste de Tukey. 
para as cultivares Lady Rosetta $(0,370 \%$ a $0,400 \%)$, Atlantic $(0,320 \%$ a $0,360 \%)$ e Asterix $(0,340 \%$ a $0,380 \%)$ e Pinelli et al. (2005). Já Feltran et al. (2004) obtiveram valores de acidez total titulável de $0,15 \%$ para a cultivar Ágata, logo após o processamento mínimo das batatas. Robles (2003) encontrou uma variação de $0,176 \%, 0,188 \%$ e $0,203 \%$ para as cultivares Monalisa, Atlantic e Jatte-Bintje, respectivamente. Feltran (2002) apresentou variação de acidez total titulável de $0,170 \% ; 0,165 \%$ e $0,160 \%$, para as cultivares Aracy, Bintje e Itacaré, respectivamente. Isso indica que há variação na acidez total titulável entre cultivares.

O teor de açúcares redutores não foi alterado com o uso do parcelamento e a dose de adubação nitrogenada e potássica (Tabela 2). Segundo Rodrigues (1990), os níveis de açúcares redutores (glicose e frutose) e sacarose podem predizer o comportamento dos materiais para processamento de chips de batata. O teor de açúcares redutores é, normalmente, o fator limitante na depreciação da cor. O limite estabelecido, na literatura, quanto ao teor de açúcares redutores, é quase consensual; para tubérculos para fritura, eles situam-se em torno de $0,2 \%$ a $0,3 \%$ da matéria úmida, inclusive para desenvolvimento de cor, pois valores inferiores deixam o produto muito branco. Bregagnoli (2006) encontrou valores semelhantes ao obtido nesse trabalho, para as cultivares Lady Rosetta, Atlantic e Asterix, com teores de $0,03 \%$ a $0,05 \%$, de $0,06 \%$ a $0,07 \%$ e de $0,06 \%$ a $0,08 \%$, respectivamente. Pádua et al. (2005) obtiveram teores de açúcares redutores de $0,033 \%$ a $0,05 \%$ para a cultivar Atlantic e $0,04 \%$ a $0,05 \%$ para a cultivar Lady Rosetta, valores abaixo do encontrado para a cultivar Ágata. Segundo Burton (1996), temperaturas influenciam no acúmulo de açúcar nos tubérculos, por causa da conversão do amido. Por isso, há variações no valor de açúcares redutores obtidos para diferentes localidades. Os teores de açúcares redutores, para a cultivar Atlantic, obtidos por este autor foram de $0,033 \%$ a $0,050 \%$, abaixo do observado para as três cultivares. Chalá et al. (2001) verificaram que a concentração de açúcares redutores no outono $(0,59 \%)$ foi o dobro da primavera $(0,28 \%)$, para as mesmas cultivares, uma vez que em temperaturas mais baixas, a conversão do amido em glicose ocorre mais rapidamente.

\section{CONCLUSÕES}

- O parcelamento da adubação de N e K em duas aplicações (50\% no plantio e 50\% na tuberização) favoreceu maior produtividade de tubérculos em relação à aplicação total do adubo no plantio e o parcelamento máximo.

- A maior dose utilizada proporcionou aumento na produção de tubérculos graúdos.
- A época de aplicação e as doses de N e K não promoveram variações significativas na massa seca, acidez total titulável, sólidos solúveis e açúcares redutores.

\section{AGRADECIMENTOS}

À Universidade Federal de Lavras - UFLA; à Coordenação de Aperfeiçoamento do Pessoal de Nível Superior (CAPES); à Universidade Estadual do Sudoeste da Bahia-UESB; e ao senhor Pedro Hugo Borré, da Fazenda Progresso II.

\section{REFERÊNCIAS BIBLIOGRÁFICAS}

ANDREATTA, A. V. Uma questão de manejo. Batata Show, Itapetinga, v. 3, n. 8, p. 42-43, dez. 2003.

ANDREU, M. A. Associação entre características agronômicas da batata nos plantios de primavera e outono no Rio Grande do Sul. Ciência e Agrotecnologia, Lavras, v. 29 , n. 5 , p. $925-929$, set./out. 2005.

ASSOCIATION OF OFFICIAL AGRICULTURAL CHEMISTS. Official methods of analysis of the Association of the Agricultural Chemists. 12. ed. Washington, DC, 1992.

ASSOCIATION OF OFFICIAL AGRICULTURAL CHEMISTS. Official methods of analysis. 15. ed. Washington, DC, 1990.

BARCELOS, D. M. Efeito do parcelamento da adubação nitrogenada em cobertura na cultura da batata. 2004. $25 \mathrm{f}$. Monografia (Graduação) - Faculdade "Dr. Francisco Maeda”, Ituverava, 2004.

BARCELOS, D. M.; GARCIA, A.; MACIEL JÚNIOR, V. A. Análise de crescimento da cultura da batata submetida ao parcelamento da adubação nitrogenada em cobertura, em um latossolo vermelho-amarelo. Ciência e Agrotecnologia, Lavras, v. 31, n. 1, p. 21-27, jan./fev. 2007.

BREGAGNOLI, M. Qualidade e produtividade de cultivares de batata para indústria sob diferentes adubações. 2006. 141 p. Tese (Doutorado em Agronomia) - Escola Superior de Agricultura "Luiz de Queiroz", Universidade de São Paulo, Piracicaba, 2006.

BREGAGNOLI, M.; BREGAGNOLI, F. C. R.; MINAMI, K.; GRATIERI, L. A.; MINCHILLO, M. Análise bromatológica de sete cultivares de batata (Solanum tuberosum L.) cultivadas na safra de verão no Sul de Minas Gerais. Horticultura Brasileira, Brasília, v. 21, p. 387-387, 2003. 
BURTON, W. G. The potato: a survey of its history and of factors influencing its: yield, nutritive value, quality and storage. Wageningen: H. Venamn; N. V. Zonen, 1996. $382 \mathrm{p}$.

CACACE, J. E.; HUARTE, M. A.; MONTI, M. C. Evaluation of potato cooking quality in Argentina. American Potato Journal, Orono, v. 71, n. 3, p. 145-153, Mar. 1994.

CARVAlHO, A. M.; ARAGÃO, F. A. D.; BRUNE, S.; BUSO, J. A. Produtividade e qualidade dos tubérculos de batata em diferentes ciclos de cultivo. In: CONGRESSO BRASILEIRO DE OLERICULTURA, 43., 2003, Recife. Anais... Recife: [s.n.], 2003. Suplemento 1, v. 21, p. 302.

CENTRO DE PESQUISAS AGRÁRIAS DA FUNDAÇÃO RURALCAJA. Patata Solanum tuberosum L. Valencia, 2007. Disponível em: <http//:www.fundacionruralcaja.org.> . Acesso em: 10 jan. 2007.

CHALÁ, C. S. de A.; PEREIRA, A. da S.; CAMPOS, A. D.; VIÉGAS, J.; SALAMONI, A. T. Variabilidade genética para teor de açúcares redutores em batatas silvestres que ocorrem no Sul do Brasil. Ciência Rural, Santa Maria, v. 31, n. 1, p. 43-47, jan./fev. 2001.

CHITARRA, M. I. F.; CHITARRA, A. B. Pós-colheita de frutas e hortaliças: fisiologia e manuseio. Lavras: UFLA, 2005. $785 \mathrm{p}$.

COELHO, A. H. R. Alterações químicas e qualidade de fritura de duas cultivares de batata (Solanum tuberosum L.) armazenadas em atmosfera modificada em temperatura ambiente e sob refrigeração. 1998. 145 p. Tese (Doutorado em Ciência dos Alimentos) - Universidade Federal de Lavras, Lavras, 1998.

FEDERAÇÃO DA AGRICULTURA DO ESTADO DO PARANÁ - FAEP. Cartilhas de classificação: hortaliças. Disponível em: <http://www.faep.com.br/comissoes/ frutas/cartilhas/hortalicas/batata.htm>. Acesso em: 15 dez. 2006.

FELTRAN, J. C. Determinação das características agronômicas, dos distúrbios fisiológicos, do estado nutricional da planta e qualidade dos tubérculos em cultivares de batata (Solanum tuberosum L.). 2002. 106 f. Dissertação (Mestrado em Agronomia) - Universidade Estadual Paulista “Júlio de Mesquita Filho”, Botucatu, 2002.
FELTRAN, J. C.; LEMOS, L. B.; VIEITES, R. L. Technological quality and utilization of potato tubers. Scientia Agricola, Piracicaba, v. 61, n. 6, p. 593-597, Nov./Dec. 2004.

FERREIRA, D. F. Programa de análises estatísticas (Statistical Analysis Software) e planejamento de experimentos. Lavras: UFLA, 2003.

INSTITUTO ADOLFO LUTZ. Normas analíticas: métodos químicos e físicos para análises de alimentos. 3. ed. São Paulo, 1985. v. 1, 533 p.

MALLMANN, N. Efeito da adubação na produtividade, qualidade e sanidade de batata cultivada no centro-oeste paranaense. 2001. 129 f. Dissertação (Mestrado em Agronomia) - Universidade Federal do Paraná, Curitiba, 2001.

NUNES, M. U. C. Produtividade e principais problemas fitossanitários de cultivares de batata em Sergipe. Horticultura Brasileira, Brasília, v. 20, n. 3, p. 424-427, set. 2002.

PÁDUA, J. G.; MASQUITA, H. A.; MOTA, R. V.; CARMO, E. L. Características qualitativas de alguns cultivares de batata de plantio outonal em duas regiões de Minas Gerais. Horticultura Brasileira, Brasília, v. 23, n. 2, 2005. Suplemento. CD-ROM.

PASCHOALINO, J. E.; NISIDA, A. L. A. C.; GARCIA, E. E. C.; TOCCHINI, R. P. Prevenção do escurecimento em batatas frescas descascadas e fatiadas. Coletânea do Instituto de Tecnologia de Alimentos, Campinas, v. 23, n. 2, p. 185-193, 1993.

PAULETTI, V.; MENARIM, E. Época da aplicação, fontes e doses de potássio na cultura da batata. Scientia Agrária, Curitiba, v. 5, n. 1/2, p. 15-20, 2004.

PINELLI, L. L. O.; MORETTI, C. L.; ALMEIDA, G. C.; SANTOS, J. Z.; ONUKI, A. C. A.; NASCIMENTO, A. B. G. Caracterização química e física de batatas Ágata minimamente processadas, embaladas sob diferentes atmosferas modificadas ativas. Pesquisa Agropecuária Brasileira, Brasília, v. 40, n. 10, p. 1035-1041, out. 2005.

REIS JÚNIOR, R. dos A.Produção, qualidade de tubérculos e teores de potássio no solo e no pecíolo de batateira em resposta à adubação potássica. 1995. 108 f. Dissertação (Mestrado em Fitotecnia) - Universidade Federal de Viçosa, Viçosa, 1995. 
ROBLES, W. G. R. Dióxido de carbono via fertirrigação em batateira (Solanum tuberosum L.) sob condições de campo. 2003. $160 \mathrm{f}$. Tese (Doutorado em Agronomia) Escola Superior de Agricultura Luiz de Queiroz, Piracicaba, 2003.

RODRIGUES, N. S. Avaliação tecnológica e sensorial de novos genótipos de batata (Solanum tuberosum $L$.) para industrialização na forma de pré-fritas congeladas. 1990.
177 f. Dissertação (Mestrado em Agronomia) - Universidade Estadual de Campinas, Campinas, 1990.

SOUTHGATE, D. A. T.Determination of foods carbohydrates. London: Elsevier Applied Science, 1991. 232 p.

VIEIRA, F. de C.; SUGIMOTO, L. S.; VITTI, G. C.; COSTA, M. C. Importância da adubação na cultura da batata. Batata Show, Itapetinga, v. 2, n. 5, p. 16-17, set. 2002. 